\title{
A Rare Complication: Perioral Burn Related to Electrocautery Use during Adenotonsillectomy
}

\author{
Erkun Tuncer $^{1}$, Sadık Şentürk ${ }^{2}$ \\ ${ }^{1}$ Department of Otolaryngology_-Head and Neck Surgery, Mevlana (Rumi) University Hospital, Konya, Turkey; ${ }^{2}$ Department of \\ Plastic and Reconstructive Surgery, Mevlana (Rumi) University Hospital, Konya, Turkey. \\ Email: etuncer@mevlana.edu.tr, ssenturk@mevlana.edu.tr
}

Received February $22^{\text {nd }}, 2013$; revised March $25^{\text {th }}, 2013$; accepted April $1^{\text {st }}, 2013$

Copyright (C) 2013 Erkun Tuncer, Sadık Şentürk. This is an open access article distributed under the Creative Commons Attribution License, which permits unrestricted use, distribution, and reproduction in any medium, provided the original work is properly cited.

\begin{abstract}
Electrocautery is frequently used for incisions and bleeding control during adenotonsillectomy which is one of the most commonly performed pediatric surgical procedures. Although cases of perioral burn related to electrocautery use are rarely reported complications in literature, they account for a significant portion of malpractice lawsuits. The use of insulated surgical tools and lip protective equipment, careful surgery, and the frequent control of surgical equipment may decrease the number of this complication. This study examines whether a rarely reported complication related to perioral burn is indeed rarely seen or whether there are problems in reporting the real rates because it is evaluated to be a case of malpractice, and the protective factors that will prevent this problem. Consequently, it is underlined that this complication, which is more frequently seen than it is reported, should be a part of preoperative information process and the consent form.
\end{abstract}

Keywords: Burn; Adenotonsillectomy; Tonsillectomy; Malpractice; Perioral Burn

\section{Introduction}

The most frequently reported complications related to adenotonsillectomy, which is one of the most commonly performed pediatric surgical procedures, include bleeding, pain, dehydration, fever, airway obstruction related to edema, nasopharyngeal stenosis, voice change, and velopharyngeal insufficiency [1,2-4]. The rate of perioral burns after adenotonsillectomy is between $0.01 \%$ and $0.04 \%$ according to literature [5-7]. Although cases of perioral burn related to electrocautery use are rarely reported complications in literature, they account for a significant portion of malpractice lawsuits [1]. The use of insulated surgical tools and lip protective equipment, careful surgery, and the frequent control of surgical equipment may decrease the number of this complication $[7,8]$. Although perioral burn cases have been rarely reported, different stages of this complication is frequently seen and therefore we believe that perioral burn as a complication should be included in the preoperative information process and in the content of the consent form.

\section{Case Report}

A 10-year-old male patient presented with a complaint of deep injury on his lip. The patient's physical examination demonstrated that he had a third-degree burn of about 2 $\mathrm{cm}$ in size covering the skin, mucosa, and the orbicular muscle on his lower lip's right comissure and he was hospitalized for treatment (Figure 1). The patient's medical history revealed that he had had an adenotonsillectomy procedure performed under general anesthesia because of chronic adenotonsillitis at another medical center 3 weeks before his presentation at our clinic. His routine pre-op lab results were normal. The necrotic tissue on the lower lip was debrided under general anesthesia and the oral mucosa was repaired with 5-0 absorbable suture. Following the repair of the orbicularis oris muscle, which was dissected on both sides of the defect, with 4-0 absorbable suture, the skin was primarily closed with 6-0 polypropylene suture. The patient's post-op course was without any problems and the result was satisfactory (Figure 2).

\section{Discussion}

Perioral burn is a rarely reported complication $(0.01 \%$ $0.04 \%$ ) when its incidence rate is compared to complications like bleeding, pain, dehydration, fever, airway obstruction related to edema, nasopharyngeal stenosis, voice 


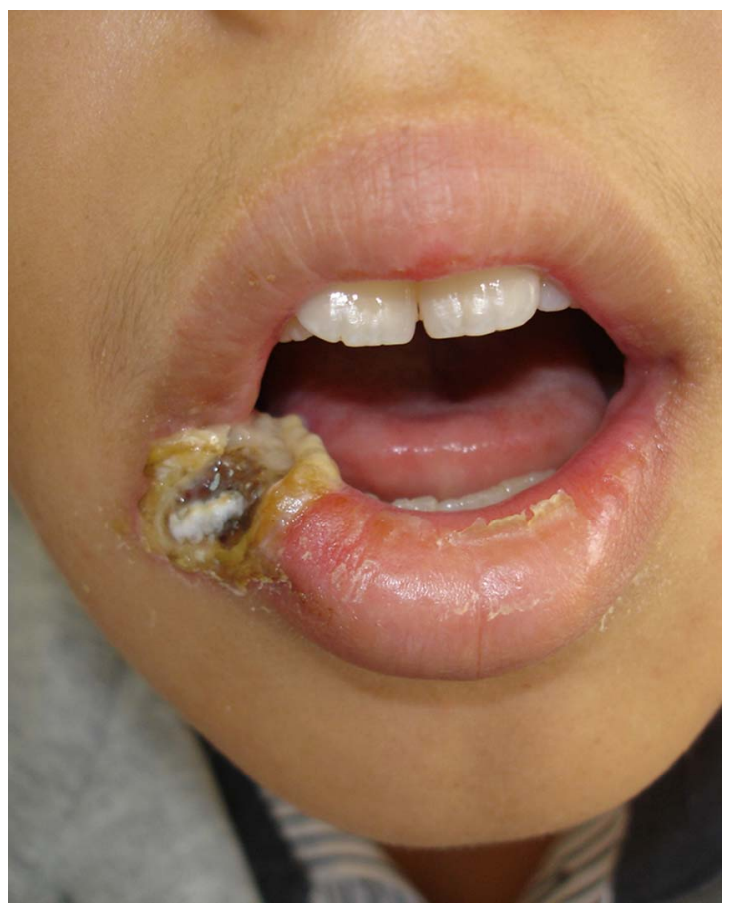

Figure 1. Preoperative view.

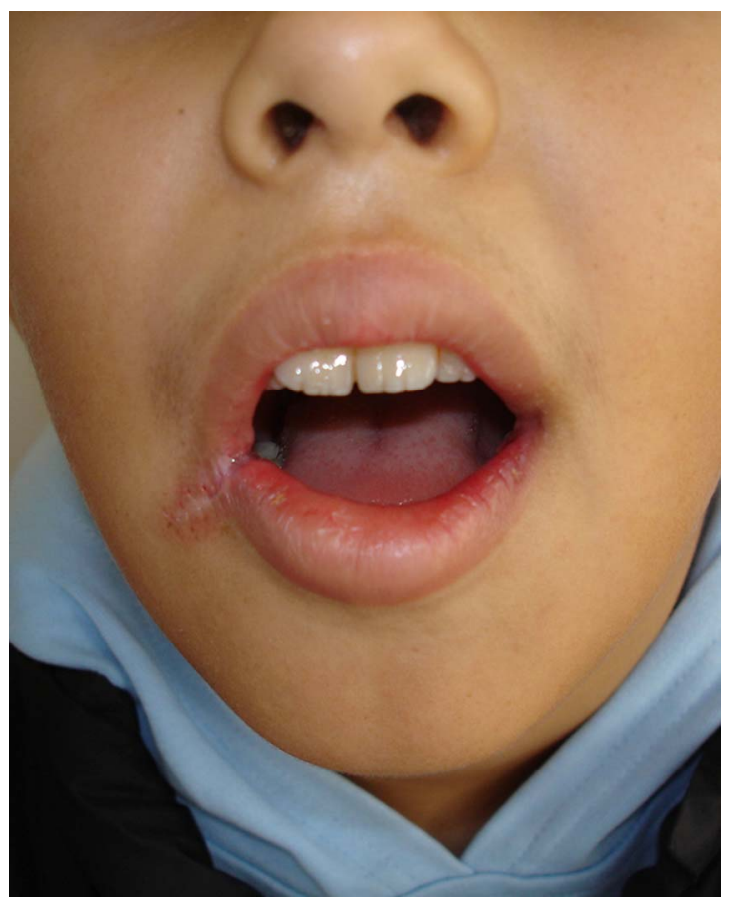

Figure 2. Postoperative view.

change, and velopharyngeal insufficiency which are frequently reported related to the adenotonsillectomy procedure [5-7]. Although cases of perioral burn related to electrocautery use are rarely reported complications in literature, they account for a significant portion of malpractice lawsuits [1,7].

While $81 \%$ of perioral burns that develop during ade- notonsillectomy procedures are first-degree, $12 \%$ of them are third-degree burns [7]. First-degree and second-degree burns can frequently be healed by antibiotic ointments without having to perform surgical procedures. Third-degree perioral burns, however, might necessitate advanced reconstructive surgical procedures depending on the size of the defect. Though rarely seen, when burns include the oral comissure they might cause aesthetic and functional losses like microstomia. The period following the separation of the eschar tissue from the surrounding healthy tissues is the most viable period for the surgical reconstruction of third-degree burn cases [9].

Electrocautery is frequently used for incisions and hemostasis in oropharyngeal surgery. Perioral burns are most commonly caused by monopolar cautery use which is followed by the coblation technique. Bipolar and aspiration cautery result in relatively less injury. The defects of the tip of the electrocautery device are most commonly identified as the cause of perioral burns $[7,8]$. Other than these causes, oropharyngeal burns were defined as resulting from the inflammation of the flammable anesthetic gases which infiltrate into the surgical site related to the use of intubation tubes without balloons [ 6 , $10]$.

The use of endotracheal tubes with balloons may decrease the risk of complications related to inflammation by reducing the amount of oxygen-rich gas leaks into the surgical site [10]. Aspiration that continues during the whole procedure may prevent inflammation by blocking the accumulation of flammable gas in the surgical site. Surgical techniques have been defined in order to prevent burns caused by leaks in the electrocautery device $[8,11]$. In addition to these techniques, a careful check of the insulation errors of the surgical equipment during the procedure will bring about adequate protection. Further, the use of protective barriers and lip protecting equipment that increases vision and decreases potential injuries for oropharyngeal procedures prevents injuries in this site. These devices increase the intraoral vision of the tonsils and may prevent potential injuries in the lateral oral comissure.

Tonsillectomy and adenotonsillectomy surgeries account for the most frequent malpractice complaints in otorhinolaryngological procedures [12]. When the rates of malpractice complaints following tonsillectomy or adenoidectomy are evaluated (bleeding $17.5 \%$, airway burns $1.5 \%$, burns $18.2 \%$, related to consent $5.8 \%$, related to medication $5.8 \%$, residual tissue/recurrence $5.8 \%$ ) it is seen that burns are the most frequent malpractice claims [1]. Another study states that while physicians think that the perioral burn complication is $4 \%$, parental observation puts the figure to $14 \%$ [13]. The differences between these data suggest that the reporting of perioral burns at different stages is not being done adequately and 
correctly. The evaluation of this complication as malpractice by physicians remains as a block against correct reporting and data collection. We believe that informing the patient and patient's relatives about perioral burns as complications in re-op information processes and consent forms will overcome

\section{Conclusion}

There are a limited number of sound studies in literature on perioral burn which is a possible complication of adenotonsillectomy. Perioral burn can be a significant complication that delays healing and that may leave permanent marks. Protective barriers should be used; careful surgical and observational measures should be taken in order to prevent this anticipated complication. Pre-op information talks and consent forms should include this possible complication.

\section{REFERENCES}

[1] A. R. Simonsen, J. A. Duncavage and S. S. Becker, "A Review of Malpractice Cases after Tonsillectomy and Adenoidectomy," International Journal of Pediatric Otorhinolaryngology, Vol. 74, No. 9, 2010, pp. 977-979. doi:10.1016/j.ijporl.2010.05.029

[2] D. J. Spencer and J. E. Jones, "Complications of Adenotonsillectomy in Patients Younger than 3 Years," Archives of Otolaryngology-Head \& Neck Surgery, Vol. 138, No. 4, 2012, pp. 335-339. doi:10.1001/archoto.2012.1

[3] L. B. Johnson, R. G. Elluru and C. M. Myer III, "Complications of Adenotonsillectomy," Laryngoscope, Vol. 112, No. 8, 2002, pp. 35-36.

[4] T. Q. Gallagher, L. Wilcox, E. McGuire and C. S. Derkay, "Analyzing Factors Associated with Major Complications after Adenotonsillectomy in 4776 Patients: Comparing Three Tonsillectomy Techniques," Otolaryngology-Head and Neck Surgery, Vol. 142, No. 6, 2010, pp. 886-892. doi:10.1016/j.otohns.2010.02.019

[5] M. J. Reilly, G. Milmoe and M. Pena, "Three Extraordinary Complications of Adenotonsillectomy," International Journal of Pediatric Otorhinolaryngology, Vol. 70, No. 5, 2006, pp. 941-946. doi:10.1016/j.ijporl.2005.09.023

[6] M. Tsuchida, K. Sakuma, M. Maruyama, H. Hanazawa, M. Urano and K. Shimoji, "Oro-Pharyngeal Burn during Electrodissection of the Adenoid and Tonsil," Masui, Vol. 46, No. 7, 1997, pp. 959-961.

[7] M. J. Nuara, et al., "Perioral Burns after Adenotonsillectomy: A Potentially Serious Complication," Archives of Otolaryngology—Head \& Neck Surgery, Vol. 134, No. 1, 2008, pp. 10-15. doi:10.1001/archoto.2007.5

[8] T. R. Lowry and J. R. Workman, "Avoiding Oral Burns during Electrocautery Tonsillectomy," Ear, Nose \& Throat Journal, Vol. 88, No. 2, 2009, pp. 790-792.

[9] M. Keskin, Z. Tosun, A. Duymaz and N. Savaci, "Perioral Electrical Burn in Children: Case Report," Ulusal Travma ve Acil Cerrahi Dergisi, Vol. 14, No. 4, 2008, pp. 326-329.

[10] R. N. Kaddoum, E. J. Chidiac, M. M. Zestos and Z. Ahmed, "Electrocautery-Induced Fire during Adenotonsillectomy: Report of Two Cases," Journal of Clinical Anesthesia, Vol. 18, No. 2, 2006, pp. 129-131. doi:10.1016/j.jclinane.2005.09.032

[11] U. K. Shah, "A Simple Suggestion to Reduce Perioral Burns during Adenotonsillectomy," Archives of Otolaryngology—Head \& Neck Surgery, Vol. 134, No. 6, 2008, pp. 673-673. doi:10.1001/archotol.134.6.673-b

[12] G. Nikoghosyan-Bossen, A. Hauberg and P. Homøe, "Systematic Analysis of Ear-Nose-Throat Malpractice Complaints May Be Beneficial for Patient Safety," Danish Medical Journal, Vol. 59, No. 2, 2012, p. A4422.

[13] D. Mistry and G. Kelly, "Consent for Tonsillectomy," Clinical Otolaryngology \& Allied Sciences, Vol. 29, No. 4, 2004, pp. 362-368. doi:10.1111/j.1365-2273.2004.00818.x 